\title{
The New Mechanical Engineering Curriculum at the University of Michigan
}

\author{
GRETAR TRYGGVASON \\ Mechanical Engineering Department \\ Worcester Polytechnic Institute \\ MiCHAEL THOULESS
Department of Mechanical Engineering
The University of Michigan \\ Deba DutTA \\ Department of Mechanical Engineering \\ The University of Michigan
}

Steven L. Ceccio

Department of Mechanical Engineering

The University of Michigan

DAwn M. TILbURY

Department of Mechanical Engineering

The University of Michigan

\section{AbSTRACT}

This paper describes the new undergraduate program in the Department of Mechanical Engineering and Applied Mechanics at the University of Michigan, Ann Arbor. The restructuring of the program was initiated by a comprehensive review in 1992 that included surveys of alumni, students, and industrial representatives, as well as faculty assessment of current trends and future needs. The program is intended to address the changing backgrounds of incoming students, to prepare the students for new and diverse challenges in the workplace, and to provide a structure for the curriculum to evolve with changing technology. The new curriculum consists of three integrated courses in Design and Manufacturing, two Laboratory courses, and several redesigned courses in the Engineering Sciences. The redesigned program provides students with extensive hands-on experience, a comprehensive experience in teamwork and technical communication, and the opportunity to exercise and develop their creativity.

\section{INTRODUCTION}

Undergraduate programs in engineering must first and foremost provide the students with a general education and help them develop analytical and critical thinking skills. In addition, engineering programs seek to provide students with the necessary skills to launch successful technical careers. The engineering curriculum must therefore evolve as technical knowledge increases and the environment where these skills are applied changes. Universities in the United States have granted engineering degrees for over one hundred years and during this time the curriculum has changed in major ways. Early engineering curricula focused on practical skills that could be applied immediately in the field, but shortly after the middle of the century the emphasis changed to providing a solid foundation in engineering science, leaving the practical training to the employer.

During the last few decades, changes in the education of mechanical engineering have been evolutionary, rather than revolutionary. It is the consensus of many educators, government officials, and industrial leaders ${ }^{1}$ that the changes have not been sufficient to keep up with the rapidly changing role of the engineer. In particular:

1. The preparation and the composition of the student body entering engineering has changed considerably. Engineering now attracts students from all sections of society, who often have little knowledge of the workings of mechanical devices and little hands-on experience. Many of these students select engineering because they believe it is a solid education that provides a reasonably secure income potential, rather than because of a strong interest in the technical aspects of the profession.

2. The work environment for the beginning engineer has become much more competitive, requiring individuals to communicate their ideas more effectively than ever before and to be cognizant of social and economic factors outside the traditional domain of engineering. Success in engineering has therefore become increasingly dependent on proficiency in skills that go far beyond technical ability.

Both of these factors require changes in the engineering curriculum that cannot be addressed by modification of the content of individual courses, or by minor changes in the course requirements.

The present paper describes curriculum revisions that have taken place in the Department of Mechanical Engineering and Applied Mechanics at the University of Michigan, Ann Arbor, during the last few years. The changes were designed to meet the challenges listed above and to provide the students with a broad preparation for success in their engineering careers, yet preserve much of the strong foundation in engineering sciences that characterized the program prior to the change.

\section{BACKGROUND}

The Department of Mechanical Engineering and Applied Mechanics (MEAM) at the University of Michigan awards a large number of baccalaureate degrees every year. ${ }^{2}$ The Department is usually also one of the top ranked programs in mechanical engineering in the United States. ${ }^{3}$ The curriculum that was required for a degree in Mechanical Engineering at the University of Michigan in 
the fall of 1992 is shown in figure $1{ }^{4} \mathrm{~A}$ total of 128 credit hours were required for graduation ( 16 credits for 8 semesters). These credits were distributed between general education courses and program specific ones. The distribution satisfied the ABET requirements of 1992, and while detailed course requirements may vary, the program was typical of engineering programs in the early nineties.

Early in 1992, a newly-appointed chairman of the Department appointed an Undergraduate Curriculum Review Committee to evaluate the status of the department's undergraduate program. The committee was charged with examining the undergraduate curriculum as a whole, and to make recommendations about changes in both the structure and the content of the program. The Undergraduate Curriculum Review Committee consisted of three faculty members, two undergraduate student members, and a former graduate of the department. The committee began with extensive data gathering, including surveys of alumni and students, information about other programs in the United States, and consultations with the faculty and the Department External Advisory Board (consisting of representatives from industry). An alumni survey was carried out during the winter term of 1993. Student surveys were conducted at the end of fall term 1992 and in the winter term 1993.

The alumni survey consisted of a questionnaire created in consultation with a staff person from the College of Engineering that was distributed to the classes of 1987, 1982 and 1972.5 The survey was designed to provide answers to the following questions:

- What are the graduates of the Department doing?

- What skills do they need in their professional life?

\section{Subjects required by all programs (56 hrs.) Mathematics $115,116,215,216$ \\ English 125, Intro. Composition Engineering 103, Computing Chemistry 130 and 125 Physics 140/141 and 240/241 Senior Technical Communications Humanities and Social Sciences \\ Advanced Mathematics (3 hrs) Elective \\ Related Technical Subjects (17 hrs.) \\ MSE 250 Principles of Engr. Materials \\ ME 101 Intro. To CAD \\ ME110 Statics \\ ME210 Intro to Solid Mechanics ME240 Intro to Dynamics \\ EECS 314 Cct. Analyts and Electronics \\ EECS 314 Cct. Analyts and Electronics Lab \\ Program Subjects (33 hrs.) \\ ME 236 Thermodynamics \\ ME 281 Mech. Behav. of Engr. Materials \\ ME 320 Fluid Mechanics I \\ ME 350 Mech. Design I \\ ME 360 Dynamics of Mech. Systems \\ ME 370 Heat Transfer \\ ME 395 Thermal-Fluids Lab \\ ME 450 Mech Design II \\ ME 461 Automatic Controls}

Technical Electives (15 hrs)

Free Electives $(4 \mathrm{hrs})$

Total

Figure 1. The Mechanical Engineering program in 1992.
- How well did the Department prepare them?

Of the 500 surveys sent out, 180 were returned for a (relatively high) $35 \%$ return rate. Of those responding over two thirds had an advanced degree or were working on one. All were employed or attending school. Most were currently working for large companies with over 1000 employees. The largest group worked for automotive and related industries. Overall, the graduates (or at least those who responded) were a successful group. Over a third of the senior alumni were in managerial positions, and over $20 \%$ were corporate executive officers, presidents, or vice presidents. Over one third of the most junior alumni described themselves as designers and product development engineers. A large number had worked for only a small number of companies (one or two) during their careers. Somewhat interestingly, this number was only slightly higher for those who graduated in 1972 than for those who graduated in 1982. The results suggest that a fairly large group of graduates started as design engineers or product development engineers and then moved into a managerial position within the same (or a comparable) company.

While the employment data provided important background information, the key part of the survey addressed the professional needs of the alumni and how well the Department had prepared them. This part of the questionnaire was divided into two categories: (i) skills and subjects learned in specific MEAM courses, and (ii) other skills needed for professional development. The alumni were asked to rank, on a scale of 1 to 5 , both the importance of each skill as well as how well MEAM and/or the University prepared them in that particular area. Figure 2 shows the response to selected categories. The top half of the table lists skills that are traditionally covered in specific mechanical engineering courses.

The same data is shown in a slightly different form in figure 3 , where the importance of each subject, ranked by the 1987 graduates, is plotted versus the preparation in a scatter plot. The open circles are the technical topics in the top half of the table and the crosses denote other professional subjects listed in the bottom half. It is, presumably, the intent and desire of the University to provide the graduates with good preparation in important subjects. Ideally, the data points should therefore be in the upper right hand quadrant, where the skills are important and the students feel that the University prepared them well. While a fair number of points fall in this quadrant, a number of points fall outside. The thermal fluid sciences (thermodynamics, fluid mechanics, and heat transfer) are not seen as particularly important, with dynamics ranking only slightly higher. While systems are seen as more important, the preparation is ranked lower. Mathematics, physics, and computer skills are seen as both important and well provided for. While a number of engineering science subjects fall in the lower right hand quadrant (good preparation but not important), the subjects in the upper left hand quadrant (important but poor preparation) are all non-science professional skills. Humanities and the Social Sciences are not seen as particularly important, but this could be because the survey explicitly asked about the importance of each subject in the professional life of the graduates. Similar plots of the data for the 1972 and the 1982 graduates show the same general trend.

The results must be interpreted with some care since graduates are likely to feel more strongly the need for skills where they have had little preparation, and may have less appreciation for knowledge that has become second nature. Nevertheless, the data in figures 2 and 3 suggests strongly that: 


\begin{tabular}{|c|c|c|c|c|c|c|}
\hline \multirow[b]{2}{*}{ Class of } & \multicolumn{3}{|c|}{$\begin{array}{l}\text { Importance } \\
\text { in my } \\
\text { professional life }\end{array}$} & \multicolumn{3}{|c|}{$\begin{array}{l}\text { How well } \\
\text { the UM } \\
\text { prepared me }\end{array}$} \\
\hline & 72 & 82 & 87 & 72 & 82 & 87 \\
\hline math and physics & 3.4 & 3.6 & 3.8 & 3.8 & 4.0 & $\overline{4.0}$ \\
\hline dynamics & 2.9 & 2.8 & 2.7 & 3.4 & 3.8 & 3.6 \\
\hline thermodynamics & 2.7 & 2.6 & 2.3 & 3.5 & 3.9 & 3.6 \\
\hline solid mechanics & 2.8 & 3.0 & 3.3 & 3.1 & 3.6 & 3.8 \\
\hline systems & 3.0 & 3.2 & 3.0 & 2.6 & 3.0 & 3.0 \\
\hline fluid dynamics & 2.3 & 2.4 & 2.3 & 3.2 & 3.5 & 3.4 \\
\hline materials & 3.2 & 3.3 & 3.5 & 3.1 & 3.5 & 3.7 \\
\hline heat transfer & 2.7 & 2.8 & 2.3 & 3.5 & 3.6 & 3.4 \\
\hline computer skills & 3.7 & 4.2 & 4.1 & 2.7 & 2.9 & 3.7 \\
\hline design and creativity & 3.8 & 4.1 & 4.2 & 3.2 & 3.2 & 2.9 \\
\hline how mechanical devices work & 3.6 & 3.9 & 3.9 & 3.3 & 3.3 & 3.1 \\
\hline manufacturing and processes & 3.4 & 3.7 & 3.6 & 2.6 & 2.7 & 2.9 \\
\hline engineering economics & 3.3 & 3.1 & 3.3 & 2.4 & 2.5 & 2.5 \\
\hline technical communication & 4.2 & 4.5 & 4.4 & 3.2 & 3.0 & 3.5 \\
\hline interpersonal skills & 4.3 & 4.6 & 4.4 & 2.6 & 2.5 & 2.4 \\
\hline professional ethics & 3.7 & 4.1 & 4.2 & 3.2 & 3.2 & 2.8 \\
\hline social/ethical aspects of work & 3.6 & 3.4 & 3.7 & 2.9 & 2.7 & 2.3 \\
\hline social sciences & 2.7 & 2.7 & 2.5 & 2.7 & 2.4 & 2.6 \\
\hline \multirow{2}{*}{ humanities } & 2.7 & 2.9 & 2.6 & 2.9 & 2.8 & 2.9 \\
\hline & \multicolumn{3}{|c|}{$\begin{array}{l}\text { 1: never used/needed } \\
\text { 2: rarely useful } \\
\text { 3: useful } \\
\text { 4: often useful } \\
\text { 5: always useful }\end{array}$} & \multicolumn{3}{|c|}{$\begin{array}{l}\text { 1: no preparation } \\
\text { 2: slight preparation } \\
\text { 3: some preparation } \\
\text { 4: good preparation } \\
\text { 5: excellent preparation }\end{array}$} \\
\hline
\end{tabular}

Figure 2. Alumni Survey. The importance of various skills versus the preparation provied by the University of Michigan, as rated by the students graduated in 72,82 , and 87.

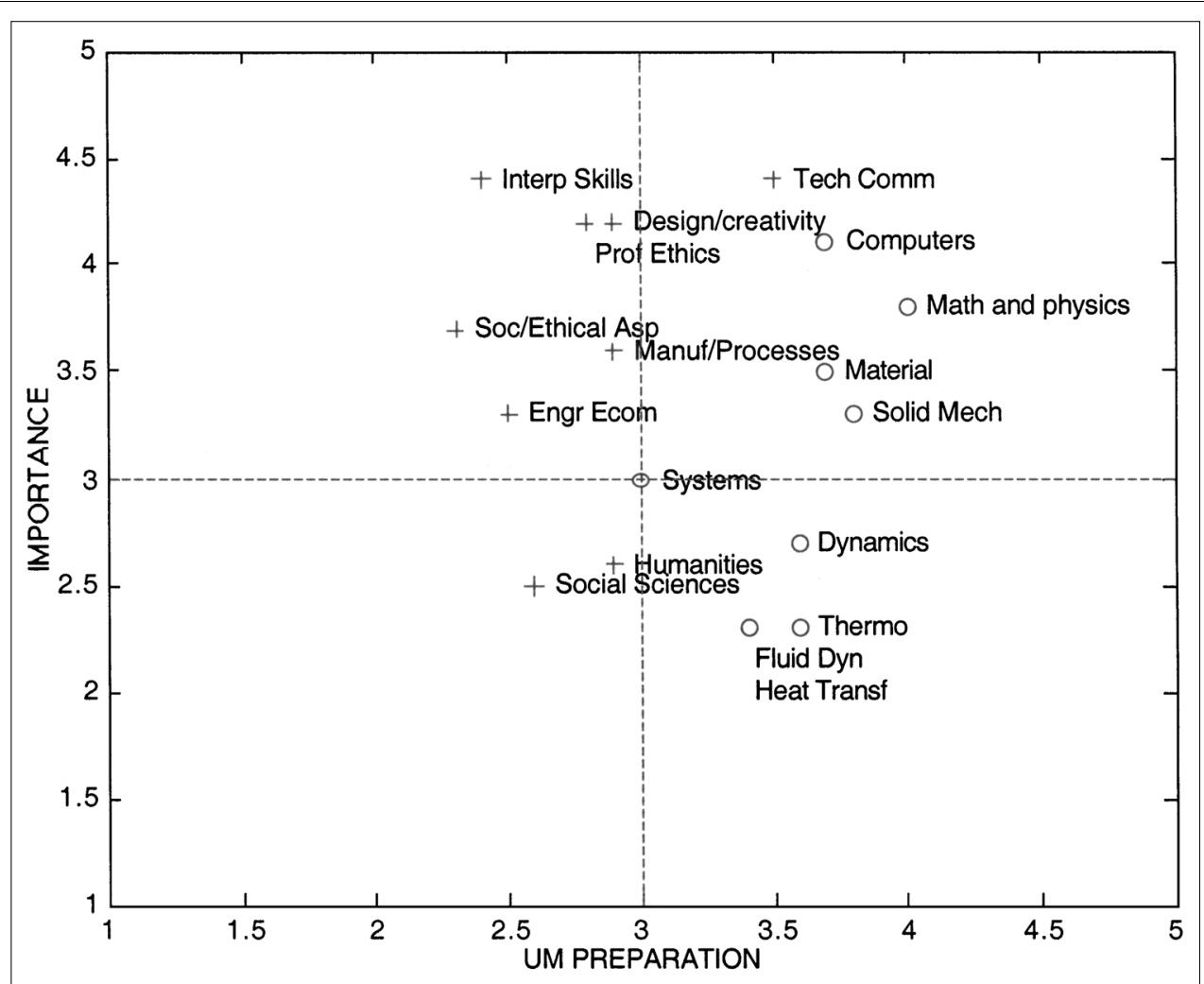

Figure 3. The importance of various skills versus the preparation provided by the University of Michigan, as rated by students who graduated in 1987. 
- The graduates felt that the University did not prepare them well in professional areas that fall beyond the engineering sciences.

- The graduates felt that a number of engineering science subjects were not very useful.

These conclusions were also supported by the responses to the open-ended questions. The alumni survey was repeated the following year with nearly identical results.

The senior surveys were distributed at meetings of the various student societies and in the senior design class during the fall of 1992. The latter proved to be highly effective and resulted in nearly $100 \%$ return rate (total of about 100 students). This survey was also repeated the following term with nearly identical results. The questionnaire distributed to the seniors was designed to provide answers to the following questions.

- Which courses were the most/least informative/enjoyable? Why?

- Why would a student's career at Michigan take longer than four years?

- What are the students' future plans?

- How well did the program satisfy the students' expectations?

The students generally expected to take more than eight terms to complete their Bachelors degree and indicated that the announced "standard" load of 16 credit was too heavy. Many of the required classes in the core curriculum contain less than four credit hours and students needed to take five courses a semester in order to graduate in four years (unless they entered the University with a significant number of advanced placement credits). Nearly all the students said that they would prefer more classes with four credit hours each so that they would have to take fewer classes overall. Many expressed an interest in joint degrees, perhaps reflecting the role of mechanical engineering as a "default" choice for some students or the choice with the best job prospects. The students generally had high expectations of themselves with two-thirds planning to go on to graduate school.

The majority of the seniors agreed with the alumni about the lack of preparation in design, real-world problem solving, and engineering economics. When asked about their favorite courses, the senior design course stood out as the most popular one. Figure 4 shows the responses to several questions from the senior survey.

The input from the Departmental External Advisory Board was more informal, consisting of verbal comments during the annual

\section{Would you be (or have been) interested in a combined 5 year BS/MS Degree? \\ $\underline{76}$ yes; $\underline{8}$ no; 10 no opinion. \\ Overall, I had sufficient hands-on and laboratory experience here $\underline{37}$ yes; $\underline{47}$ no; $\underline{2}$ no opinion \\ Overall, I had sufficient design experience here

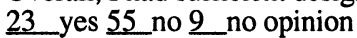 \\ Overall, there were sufficiently many "real world" exercises here $\underline{6}$ yes $\underline{78}$ no 10 no opinion \\ Overall, there was enough engineering economics in the curriculum $\underline{12}$ yes $\underline{70}$ no $\underline{14}$ no opinion \\ Overall, there was enough emphasis placed on communication in the curriculum \\ $\underline{31}$ yes $\underline{52}$ no $\underline{9}$ no opinion}

Figure 4. Response to selected question on the senior survey. visit of the committee. In general, these were consistent with the results of the surveys. The results of the surveys appear also to be in agreement with the results of other studies. ${ }^{6}$

\section{RECOMMENDATIONS}

The undergraduate Mechanical Engineering program at Michigan has been consistently well rated $^{3}$, yet it was clear that the program was not reaching its full potential in providing the graduates with the preparation most useful for their professional success. The members of the MEAM Undergraduate Curriculum Review Committee felt that the reason for this was-at least in part-due to changes that had taken place in the last few decades. Two of the most important changes are:

- The background of the incoming students is changing rapidly. In the past, most of the incoming students had considerable hands on experience, and it could be assumed that students had some experience with basic tools and common machinery. Today, however, entering students may have little or no exposure to mechanical devices.

- Industry has increasingly come to rely upon a team approach to problem solving. Furthermore, the increasing mobility and the diverse responsibilities of the average engineer requires more emphasis on teamwork experience and communication skills.

While these two aspects were the key ones, the committee felt there where a number of other drivers for change, some of which would be better addressed at the level of individual courses. Those include, for example, the proliferation of new problem solving tools (such as engineering software packages) which permit more emphasis on design and optimization, and rapidly changing technology that necessitates introduction of new material into the core curriculum. The committee also acknowledged that the diversity of students entering the program and the range of opportunities open to the graduates would possibly lead to very divergent career paths.

From these observations, the committee identified the following objectives to be addressed in the new curriculum:

- Experience with complex mechanical devices must come from modern instructional laboratories and the design course sequence.

- Teamwork and communication skills must be emphasized throughout the curriculum.

- The formulation of engineering problems and the relevance and use of the solution itself should be emphasized over mechanical solution techniques.

- Students should be given the opportunity to customize their undergraduate degrees through both technical and free electives.

To incorporate these recommendations into the curriculum, the committee proposed a number of specific changes to the structure of the MEAM program. The key intent of the committee was to provide students with a much broader preparation in engineering by emphasizing formal instruction in a number of areas beyond the engineering sciences. The changes were also designed to promote continuing evolution of both the engineering sciences and other courses by removing as many barriers, such as strict boundaries between topics, as possible. To minimize disruption to students and faculty, the committee proposed a gradual change where the 1992 
curriculum would evolve into the new structure over a few years. The specific changes recommended by the curriculum review committee were:

- Introduction of a sophomore level course in Design and Manufacturing, resulting in a three-course sequence culminating in the senior level design course.

- Consolidation of all required laboratories into a junior and a senior laboratory sequence with integrated teamwork training and written and oral communication components.

- Restructuring the required MEAM curriculum into five core sequences in Design and Manufacturing, Dynamics and Controls, Materials and Structures, Thermal/Fluid Sciences, and Instructional Laboratories, and integrating the presentation in each sequence as much as possible.

- Reorganization of the core curriculum into four credit hour courses so that students could enroll in four, four-credit hour courses per semester for the majority of the required core curriculum.

The recommendations of the review committee were communicated to the Mechanical Engineering faculty by memoranda and at several faculty meetings. After considerable discussions, the faculty approved the program, in principle, with the understanding that all specific changes would be brought to the faculty for separate discussion and vote.

Following the review conducted by Department of Mechanical Engineering and Applied Mechanics, other departments in the College of Engineering at Michigan have conducted similar surveys and made major changes in their programs. The result of these departmental initiatives was the formation of a college level committee, appointed to evaluate the common core required of all engineering undergraduates, and to ensure coherence between the various curriculum reforms in the College. The committee started working in the summer of 1995 and delivered its report to the faculty in April of 1996. The faculty voted with a large majority to adopt its recommendations.

The result of the College review was an action plan entitled "Michigan Curriculum 2000." The report details several specific recommendations, including:

- Introduction of a Freshmen Engineering class.

- Restructuring of all departmental core sequences into four credit hour classes.

- Introduction of communication, teamwork, ethics, environmental awareness, treatment of uncertainty, and computing as "threads" across the curriculum.

The College recommendations were in complete agreement with most of the MEAM changes and the proposed changes therefore affected mostly courses outside the department. The introduction of threads into the required courses did, however, go beyond the MEAM recommendations. The new curriculum, incorporating both the recommendations of the MEAM review committee as well as the "Michigan Curriculum 2000" proposal is shown in figure 5 , where the various topics are listed in the same format as in figure 1.

\section{IV.IMPLEMENTATION AND CURRENT STATUS}

The MEAM curriculum changes coincided with considerable influx of new faculty. This influx of fresh faces and ideas, combined

\begin{tabular}{|lcr|}
\hline \multicolumn{4}{|c|}{ Subjects required by all programs (52 } & hrs) \\
Mathematics & 4 courses & 16 \\
Chemistry & 1 course & 4 \\
Physics & 2 courses & 8 \\
Humanities & $4-5$ courses & 16 \\
Computing & 1 course & 4 \\
Intro. Engineering & 1 course & 4 \\
ME Program Subjects & $\mathbf{4 4}$ hrs) & \\
Laboratories & 2 courses & 8 \\
Design/Manufacturing & 3 courses & 12 \\
Solid Mech+Materials & 2 courses & 8 \\
Dynamics/Systems/Ctrls & 2 courses & 8 \\
Thermal/fluid Sciences & 2 courses & 8 \\
Related Technical Subjects & $\mathbf{8}$ hrs) \\
Required EE elective & 1 course & 4 \\
Adv. Math elective & 1 course & 4 \\
Technical Electives & $3-4$ courses & 12 \\
Free Electives & $3-4$ courses & $\mathbf{1 2}$ \\
Total & $\mathbf{1 2 8}$ \\
\hline
\end{tabular}

Figure 5. The new program listed in a similar format as the old program in Figure 1.

with a long tradition of dedication to undergraduate teaching among the senior faculty, resulted in considerable enthusiasm among the faculty for the new curriculum. The proposed changes were discussed extensively. Concerns raised included both pedagogical issues, such as whether the larger but fewer courses would make it more difficult for the students to gain exposure to many different subjects, and practical aspects, such as what effects the new curriculum would have on the teaching load. With the overwhelming support of the faculty, the implementation of the new program has progressed relatively smoothly.

Implementation of the reforms initially focused on the Design and Manufacturing and the Laboratory sequences. Two courses in design at the junior and senior level were already in place in 1992. A sophomore level course, Design and Manufacturing I, was introduced in the fall of 1994. In the sophomore course, the students are introduced to engineering design, various manufacturing processes, Computer Aided Design, and basic machining operations, including numerically controlled machining. Students work in teams (3-4 students per team) on a design project (usually the redesign of a simple consumer product such as a flashlight, stapler, computer mouse, etc.) and produce a working prototype. For more details of this class see reference. ${ }^{8}$ The junior course is a more traditional mechanical component design class, but teams of four students complete one or two design projects per term. At least one of the projects results in a working prototype. In the senior level course, students work on industry-sponsored projects and build working prototypes. All the design/manufacturing courses consist of both lectures and shop sections. Written reports and oral presentations during design reviews are an integral part of all three courses.

Prior to the 1990, all required laboratories were offered as a one credit hour addition to the various lecture classes. While some of these laboratories had been maintained and updated by interested faculty members, others had not, and in many cases the laboratories were run by teaching assistants with little guidance from the lecturing faculty. A year prior to the curriculum review, the laboratories in 
the thermal/fluid sciences had been consolidated in a single class. The laboratories of the material and mechanics course were combined with those of the dynamics course to create a second laboratory class in Winter of 1994 . These courses were transformed into a junior and senior level laboratory sequence in the Winter 1998 term. The junior level laboratory consists of one-week laboratories, a two-week midterm, and a final two-week laboratory project. The senior level laboratory consists of four extended laboratory projects that emphasize the analysis of relatively complex engineering systems. One of the senior laboratories is student designed, constituting the final examination for the class. Major emphasis is placed on technical communications and the completion of formal reports. In the junior laboratory the emphasis is on writing. In the senior laboratory, oral presentation skills are also developed. Of two lectures per week, one lecture is devoted exclusively to technical communications. All of the laboratory work is done in teams of 2-4 students.

Generally, students take one design/manufacturing or laboratory class each semester after they enter the mechanical engineering program. By concentrating teamwork and communication instruction in these courses, most students are typically involved in only one team-project per term.

Changes in the Engineering Science courses progressed more slowly. The introductory dynamics course was modified by adding one credit hour to include more instruction in the use of computational tools. The systems modeling course was changed to include introduction to control and more emphasis on the use of software tools. The control course became a technical elective, but some of the controls laboratories were transferred to the senior laboratory course. A new four credit hour course in materials science replaced two three-credit hour courses in Fall of 1997. One of the old materials science courses was a sophomore level course taught to all students in the College, and considerable overlap existed between that course and the course taught by the mechanical engineering faculty. Now the curriculum consists of a combined introduction to static and strength of materials class, followed by a combined advanced strength of materials/introduction to material science class. Two new courses in thermal/fluid sciences were introduced in the 199899 academic year. These courses replace a traditional three-course sequence in thermodynamics, fluid mechanics, and heat transfer.

The implementation of the various threads proposed by the College "Curriculum 2000" program is still ongoing. These threads consist of teamwork, communication, computing, dealing with uncertainty, ethics, and environmental awareness. Major progress has been made with teamwork and communications. Computing is still somewhat uncoordinated, but considerable exposure to computing is provided in many of the required classes. The same holds for dealing with uncertainty. Ethics and environmental awareness remain a weakness. Although addressed in some courses, a significant effort will be required to provide an integrated introduction to these topics across the curriculum. The College of Engineering is currently providing financial support and other help to the departments to complete the implementation of the various threads.

Motivated both by the need to assess the impact and implementation of Curriculum 2000 and an imminent ABET review, ${ }^{9}$ the College has established an extensive survey program for both students and alumni. The new surveys are based on the surveys conducted in 1992 and 1993 by MEAM and other departments in the College, but will now be done every year. Some aspects of the new program have been in place to allow their impact to be assessed. Teamwork, for example, has been a part of both the design/manufacturing and the laboratory courses for several years and the alumni survey conducted last year indicates that the teamwork component has been implemented very successfully. Figure 6 shows the result of the 1998 alumni survey, where students were asked to rate the quality of teamwork preparation. On a scale of $1-5$, the satisfaction has increased by more than one point between those who graduated in 1988 and those who graduated in 1996. While it is possible that part of the change is due to a change in student perspective, the increase coincides with our major effort to increase teamwork training. The alumni who graduated in 1996 also list teamwork as one of the strengths of the Program, along with the engineering science. If there still is a problem, it is perhaps the opinion of some of the seniors who feel that there is too much emphasis placed on teamwork. This is likely to be, in part, due to insufficient emphasis placed on explaining to the students why teamwork is important.

The new curriculum has provided an excellent basis from which to develop dual degrees with other programs in the Engineering College. By using the common core and the flexibility provided by free electives, several such programs have been established, including Aerospace, Chemical, Electrical, Industrial, Material Science, Manufacturing, and Nuclear Engineering. These programs have been set up in such a way that they can be completed with only one additional semester of study, yet retain the important characteristics of the two separate programs. An example of the classes required for a joint degree in Electrical Engineering and Mechanical Engineering is shown in figure 7 . The new curriculum has also made it easier to establish joint degrees with other programs beyond the College of Engineering. An extra year of study, for example, allows students to obtain a joint degree in Industrial Design and Mechanical Engineering.

\section{DisCUSSION AND CONCLUSIONS}

The new curriculum described here is a significant departure from the traditional education of mechanical engineers. While the new program retains the strong focus on engineering science characteristic of the earlier (pre-1992) program offered by the Department, the greatly increased formal emphasis on communication, teamwork, creativity, and hands-on experience is new. Indeed, while the engineering sciences used to be the sole backbone

\begin{tabular}{|l|l|c|c|c|c|c|}
\hline $\begin{array}{c}\text { Year } \\
\text { graduated }\end{array}$ & $\begin{array}{c}\text { Excellent } \\
5\end{array}$ & $\begin{array}{c}\text { Good } \\
4\end{array}$ & $\begin{array}{c}\text { Some } \\
3\end{array}$ & $\begin{array}{c}\text { Slight } \\
2\end{array}$ & $\begin{array}{c}\text { None } \\
1\end{array}$ & $\begin{array}{c}\text { Weighted } \\
\text { average }\end{array}$ \\
\hline 1988 & $11.3 \%$ & $30.2 \%$ & $26.4 \%$ & $24.7 \%$ & $7.5 \%$ & 3.13 \\
\hline 1993 & $21.3 \%$ & $35.5 \%$ & $30.3 \%$ & $13.2 \%$ & $0.0 \%$ & 3.65 \\
\hline 1996 & $41.8 \%$ & $38.0 \%$ & $17.7 \%$ & $1.3 \%$ & $1.3 \%$ & 4.18 \\
\hline
\end{tabular}

Figure 6. Response to the question "the University preparation for teamwork was:" on an alumni survey conducted in 1998. 


\begin{tabular}{|c|c|c|}
\hline \multicolumn{3}{|c|}{ Required by all programs (52 hours) } \\
\hline Mathematics & 4 courses & 16 \\
\hline Chemistry & 1 course & 4 \\
\hline Physics & 1 course & 4 \\
\hline Physics or Biology course & 1 course & 4 \\
\hline Humanities & 4-5 courses & 16 \\
\hline Computing & 1 course & 4 \\
\hline Intro. Engineering & 1 course & 4 \\
\hline \multicolumn{3}{|c|}{ ME program Subjects (40 hours) } \\
\hline Laboratories & 1 courses & 4 \\
\hline Design and Mfg. & 3 courses & 12 \\
\hline Solid Mech+Materials & 2 courses & 8 \\
\hline Dynamics/Syst/Ctrls & 2 courses & 8 \\
\hline Thermal/fluid Sciences & 2 courses & 8 \\
\hline \multicolumn{3}{|c|}{ EE program Subjects (40 hours) } \\
\hline Electrical Engr. I \& II & 2 courses & 8 \\
\hline Electromagnetics I \& II & 2 courses & 8 \\
\hline Intro to Logic Design & 1 courses & 4 \\
\hline Prog \& Intro to Data Struct & 1 courses & 4 \\
\hline Electronic Circuits & 1 courses & 4 \\
\hline Signals \& Systems & 1 courses & 4 \\
\hline Intro to Semiconductors & 1 courses & 4 \\
\hline Probabilistic Methods & 1 courses & 4 \\
\hline Technical Electives & $3-4$ course & 12 \\
\hline Total & & 144 \\
\hline \multicolumn{3}{|c|}{$\begin{array}{l}\text { EE elective, Advanced Math, and Senior Laboratory } \\
\text { requirements in the ME program are satisfied by EE courses. }\end{array}$} \\
\hline Figure 7. A joint BS degree in & chanicalar & lectrical \\
\hline
\end{tabular}

of the curriculum, this role is now shared with the engineering practice courses. The central role played by the design/manufacturing and the laboratory courses is particularly clear in figure 8, where a possible distribution of courses over eight semesters is shown. The courses have been grouped into five categories: General education, which includes courses in Humanities and Social Sciences as well as free electives; Mathematics; Basic sciences; Engineering sciences; and Engineering practice. The layout in figure 8 is based on the assumption that students complete 128 credits hours during their studies for a BS Degree. In reality, most students enter the program with advanced placement credits and can not be expected to follow this format exactly. The layout also implies that all the classes a student takes are four credit hours, whereas many courses in the social sciences and humanities, as well as some of the technical electives, are likely to remain at three credit hours. This does not, however, change the basic structure of the program.

The motivation for the changes described here is the increasingly diverse background of students entering engineering and the changing needs of students entering the workforce. In addition to preparing students better for engineering careers, the increased emphasis on non-science aspects of mechanical engineering may also encourage more students to select BS degree in engineering as a preparation for a non-engineering career such as in law and medicine. Although the new curriculum does not, perhaps, offer the flexibility originally envisioned by the MEAM Undergraduate Curriculum Review Committee, we have found that the structure allows students to pursue dual degrees relatively easily.

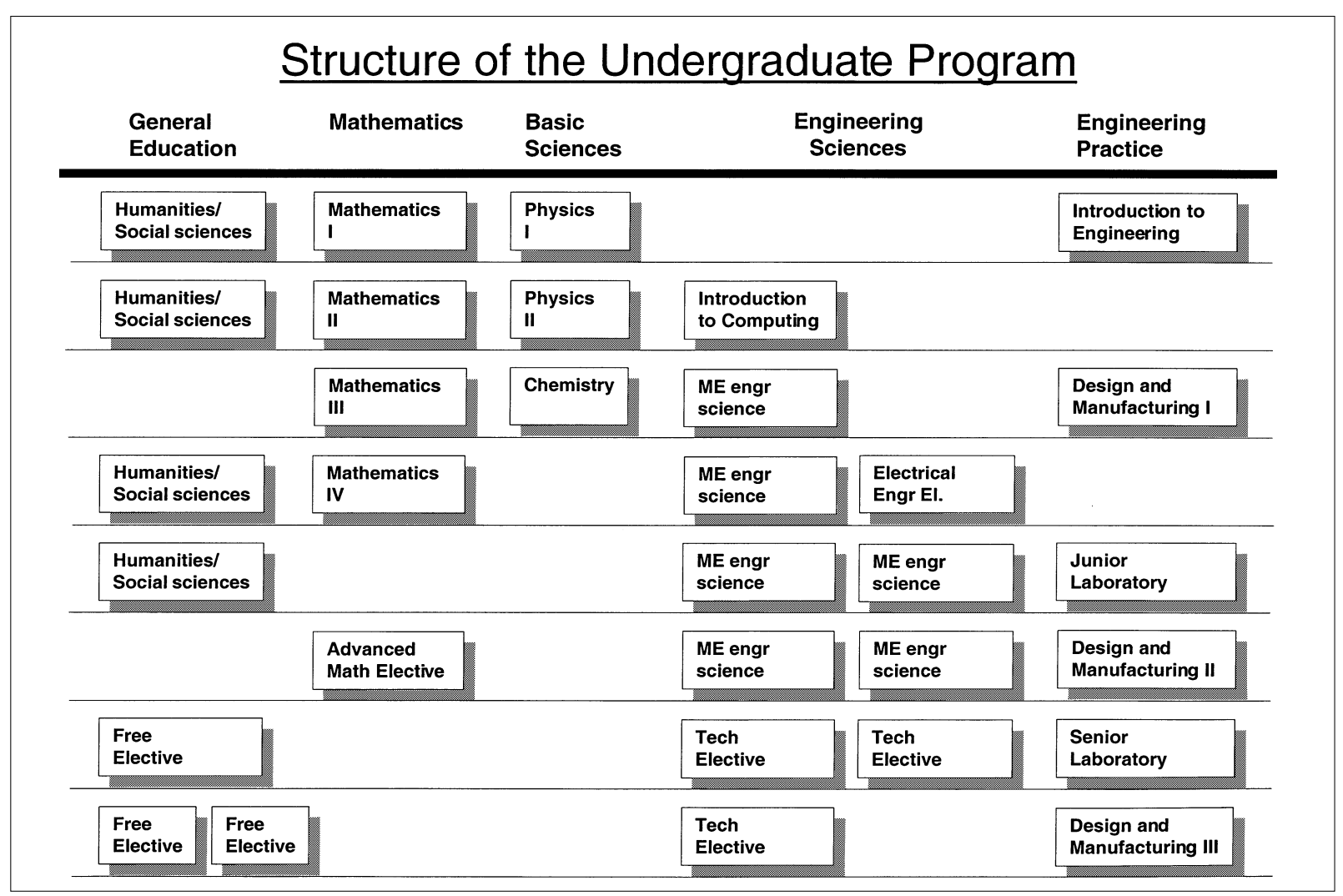

Figure 8. The layout of the new curriculum in a format where the importance of the engineering practice courses is clearly visible. 


\section{REFERENCES}

1. "Restructuring Engineering Education: A Focus on Change," National Science Foundation, NSF 95-65, 1995.

2. In 1992 the Department ranked number 3 in number of Bachelor's Degrees awarded in the US, according to the Engineering Manpower Commission (Tel.: 202 296-2237)

3. In 1995 the ME undergraduate program was ranked number three (along with six other institutions) by U.S. News E World Report.

4. The University of Michigan, College of Engineering Bulletin, 1992.

5. "1993 Alumni Survey." Report available from the Department of Mechanical Engineering and Applied Mechanics, University of Michigan.

6. "Report on Survey of Opinions by Engineering Deans and Employers of Engineering Graduates on the First Professional Degree," National Society of Professional Engineers, NSPE Publication No. 3059, 1992.

7. "Michigan Curriculum 2000," Report available from the Dean of Undergraduate Studies, College of Engineering, University of Michigan.

8. "Introducing Hands-on Experience in Design/Manufacturing Education,” D. Dutta, U. Geister, and G. Tryggvason, in Proceedings of the 1998 SMEManufacturing Education Conference, San Diego, Oct. 1998.

9. Criteria for Accrediting Programs in Engineering in the United States, Engineering Accreditation Commission, The Accreditation Board for Engineering and Technology, Inc. (ABET), http://www.abet.org/. 